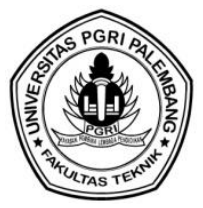

\title{
PEMANFAATAN MINYAK MENTAH (CRUDE OIL) UNTUK MENINGKATKAN STABILISASI JALAN TANAH PADA DAERAH MAKARTI JAYA KABUPATEN BANYUASIN
}

\author{
Herri Purwanto $^{1 *}$, Adiguna ${ }^{2}$, Reffanda Kurniawan Rustam. ${ }^{3}$, dan Bagus A. Budiarto ${ }^{4}$ \\ ${ }^{1234}$ Prodi Teknik Sipil Fakultas Teknik Universitas PGRI Palembang \\ ${ }^{*}$ Corresponding author, e-mail : hei_s2@yahoo.com
}

\begin{abstract}
ABSTRAK
Bahan stabilisasi tanah yang digunakan pada penelitian ini adalah pemanfaatan minyak mentah (crude oil) dengan variasi 0\%, 5\%, 10\%, 15\%, dan 20\%. Sampel tanah diambil dengan metode disturb dan undisturb sampel pada kedalaman 0,5 - $3 \mathrm{~m}$. Adapun lokasi penelitian berada di Daerah Makarti Jaya Kabupaten Banyuasin. Hasil pengujian index propertis menunjukkan bahwa tanah daerah Makarti Jaya memiliki kadar air yang tinggi yaitu mencapai $116,615 \%$ dan berat jenis tanah sebesar 1,81 gr/ $/ \mathrm{cm}^{3}$. Hasil dari pengujian pemadatan tanah standar terhadap tanah asli didapatkan kadar air optimum (W) sebesar 18\% dengan berat isi kering maksimum $(\gamma) 7,4 \mathrm{gr} / \mathrm{cm}^{3}$. Berdasarkan hasil pengujian direct shear diperoleh nilai kohesi maksimum (c) terjadi pada campuran minyak mentah (crude oil) 5\% yaitu sebesar 20,23 kPa. Nilai sudut geser maksimum dalam (ф) terjadi pada sempel tanah yang dicampur dengan minyak mentah (crude oil) sebanyak 10\% yaitu $29^{\circ}$. Nilai kuat geser ( $\tau$ ) maksimum terjadi pada sampel tanah yang dicampur dengan minyak mentah (crude oil) sebanyak 5\% yaitu 21,10 kPa. Minyak mentah (crude oil) pada persentase $5 \%$ disimpulkan dapat mengubah sifat tanah daerah Makarti Jaya yang semulanya lembek menjadi lebih keras dan dapat diterapkan di jalan tanah daerah Makarta Jaya
\end{abstract}

Kata Kunci : Makarti Jaya, stabilisasi tanah, minyak mentah, hasil pengujian

\section{PENDAHULUAN}

Kecamatan Makarti Jaya adalah sebuah wilayah yang terletak di bagian timur Kabupaten Banyuasin yang merupakan sebuah daerah transmigrasi perairan di daerah Sumatera Selatan, di mana pada saat ini sudah berkembang pesat namun masih banyak infrastruktur terutama jalan yang sangat memprihatinkan. Hal ini dikarenakan karakteristik dan jenis tanah pada daerah Makarti Jaya yang merupakan tanah liat atau lempung lunak sehingga daya dukung pada jalan masih kurang baik.

Salah satu usaha untuk memperbaiki jalan tersebut adalah dengan menstabilisasi tanah lempung lunak yaitu dengan memperbaiki sifat fisik dan merubah sifat mekaniknya melalui pencampuran bahan tambah,dan salah satunya adalah dengan minyak mentah (crude oil). Diharapkan dengan pencampuran minyak mentah (crude oil), dapat menambah daya dukung tanah dan dapat menstabilkan tanah di daerah Makarti Jaya.

\section{TINJAUAN PUSTAKA}

\section{Tanah Lempung}

Lempung merupakan tanah yang berbutir halus, tersusun dari mineral-mineral lempung dan partikel- artikel mikroskopis dan submikroskopis yang berbentuk lempengan-lempengan pipih yang halus (Das, 1995). Dimana tanah lempung lunak adalah tanah yang mengandung mineral-mineral lempung dan memiliki kadar air yang tinggi, yang menyebabkan kuat geser yang rendah. 
Lempung merupakan agregat partikel-partikel berukuran mikroskopik dan submikroskopik yang berasal dari pembusukan kimiawi unsur-unsur penyusun batuan. dan bersifat plastis dalam selang kadar air sedang sampai luas. Dalam keadaan kering sangat keras, dan tak mudah terkelupas hanya dengan jari tangan. Permeabilitas lempung sangat rendah. Pada kadar air yang lebih tinggi (basah) lempung tersebut bersifat lengket (Terzaghi,1987)

\section{Minyak Mentah (Crude Oil)}

Minyak mentah (crude oil) yang baru keluar dari sumur eksplorasi mengandung bermacam - macam zat kimia yang berbeda baik dalam bentuk gas, cair maupun padatan. Lebih dari separoh $(50-98 \%)$ (Supriharyono, 2000). Minyak mentah meliputi produk cair (natural gas liquid (NGL) termasuk didalamnya) yang diperoleh dari sumur minyak, sebagian besar berupa hidrokarbon non aromatic. Termasuk juga sejumlah yang dipakai pada proses produksi dan juga untuk transformasi energi.

Minyak mentah merupakan campuran yang kompleks dengan komponen utama alkana dan sebagian kecil alkena, alkuna, siklo - alkana, aromatik, dan senyawa anorganik. Minyak mentah mengandung sekitar 50-98\% senyawa hidrokarbon dan sisanya merupakan senyawa non - hidrokarbon (sulfur, nitrogen, oxigen, dan beberapa logam berat seperti $\mathrm{V}$, Ni dan $\mathrm{Cu}$ ).

\section{Stabilitasi Tanah}

Stabilisasi tanah dasar (subgrade) adalah usaha untuk/memperbaiki mutu tanah (daya dukung tanah) yang tidak baik dan meningkatkan mutu dari tanah agar mendapatkan kondisi tanah dasar (subgrade) yang memenuhi spesifikasi teknis yang disyaratkan. Stabilisasi tanah dasar (subgrade) bertujuan untuk meningkatkan kemampuan daya dukung tanah serta mendapatkan tanah dasar yang stabil pada semua kondisi musim dan selama umur rencana perkerasan jalan tersebut (Hardiyatmo, 2010).

Bowles, 1993:201 menyatakan bahwa stabilisasi dapat terdiri dari salah satu tindakan sebagai berikut yaitu:

a) Meningkatkan kerapatan tanah;

b) Menambah material yang aktif sehingga meningkatkan kekuatan geser tanah,;

c) Menambah bahan yang dapat menyebabkan peruhan kimiawi pada tanah;

d) Menurunkan muka air tanah dan;

e) Mengganti tanah yang jelek.

Penerapan dan keberhasilan dari tindakan tersebut sangat bergantung pada jenis dan kondisi tanah, peralatan dan metoda pengujian yang diterapkan.

Menurut (Pangurinseng Darwis, 2001), berdasarkan mekanisme kerja komposit antara massa tanah dengan bahan stabilizer.

Jenis stabilisasi tanah dapat dibedakan atas :

1. Stabilisasi kimia : yaitu stabilisasi dengan menggunakan bahan-bahan kimia memungkinkan terjadinya reaksi kimia, dan menghasilkan senyawa baru yang bersifat 
stabil dari pada senyawa yang terdapat dalam massa tanah sebelum stabilisasi dilakukan,

2. Stabilisasi fisik : yaitu stabilisasi dengan menggunakan energi yang disalurkan ke lapisan tanah, sehingga memperbaiki karakteristik lapisan sesuai dengan tujuan dari stabilisasi yang diinginkan,

3. Stabilisasi mekanis : yaitu stabilisasi dengan menggunakan material sisipan ke lapisan tanah, sehingga mampu memperbaiki karakteristik massa tanah sesuai tujuan tindakan stabilisasi yang diinginkan. Stabilisasi mekanis sering juga disebut " perkuatan tanah (reinforcement earth),

4. Stabilisasi termal : yaitu stabilisasi dengan menggunakan panas (termal) untuk membakar material tanah, sehingga kadar air kristal massa tanah menjadi sangat rendah, yang memungkinkan ikatan senyawa dalam massa tanah lebih stabil (irreversible).

\section{METODE PENELITIAN}

Metode penelitian yaitu pengujian laboratorium yang ditunjukkan pada Gambar berikut :

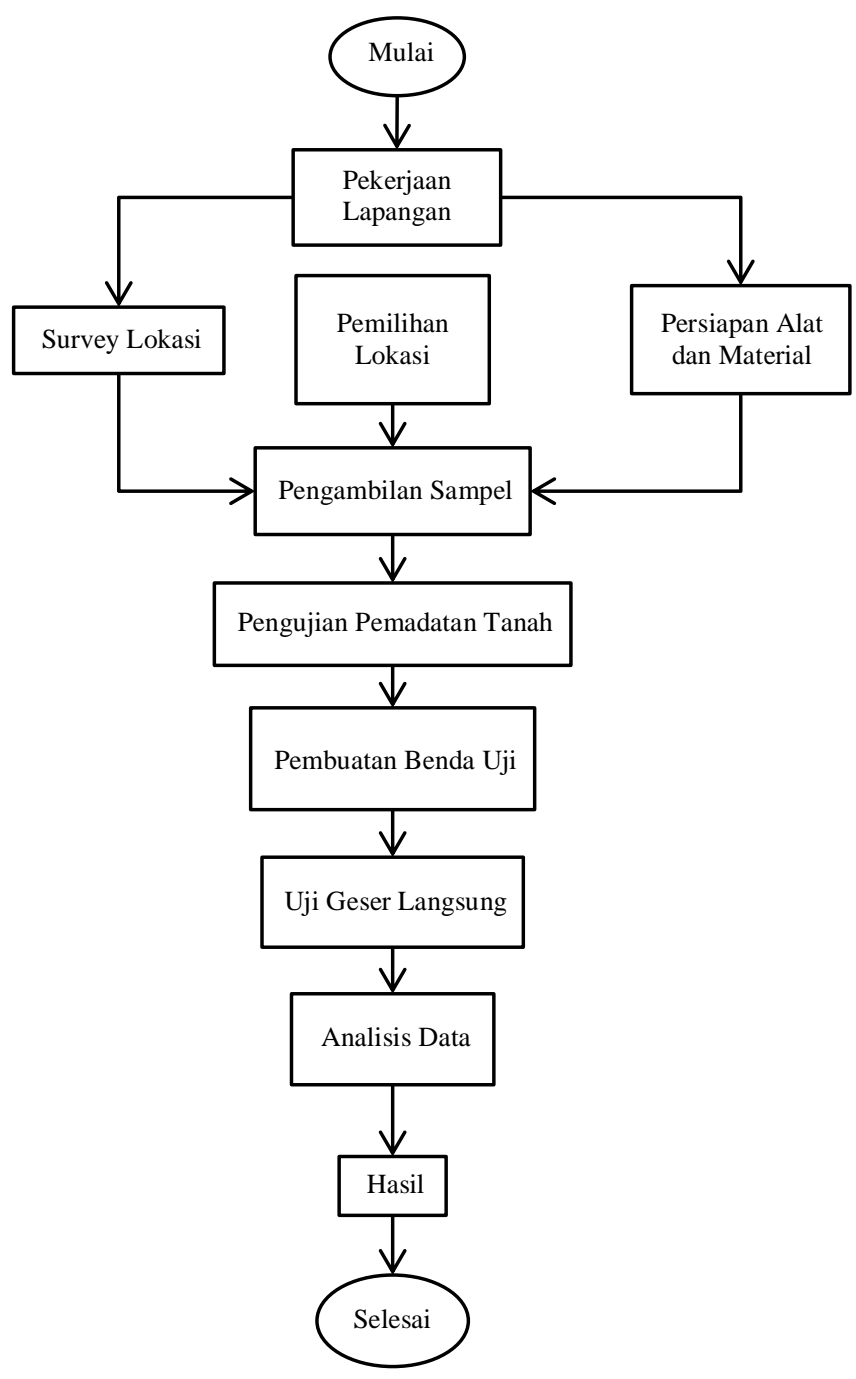

Gambar 1. Diagram Alir Penelitian 


\section{HASIL DAN PEMBAHASAN}

Hasil pengujian index properties tanah, yaitu kadar air $(\omega)$, dan berat jenis (Gs) diperlihatkan pada tabel berikut :

Tabel 1. Kadar Tanah Asli

\begin{tabular}{clcc}
\hline No. & \multicolumn{1}{c}{ Pengujian } & Simbol & Hasil \\
\hline 1 & Kadar Air Asli (Water Content) & $\omega$ & $116,615 \%$ \\
2 & Berat Jenis Tanah (Sspecific Gravity) & $\mathrm{G}_{\mathrm{s}}$ & $1,81 \mathrm{gr} / \mathrm{cm}^{3}$ \\
\hline
\end{tabular}

Hasil pengujian tanah standar terhadap tanah asli didapatkan kadar air optimum (W) didapat $18 \%$ dengan berat isi kering maksimum $(\gamma) \quad 7,4 \mathrm{gr} / \mathrm{cm}^{3}$ yang diperlihatkan pada gambar 2 berikut :.

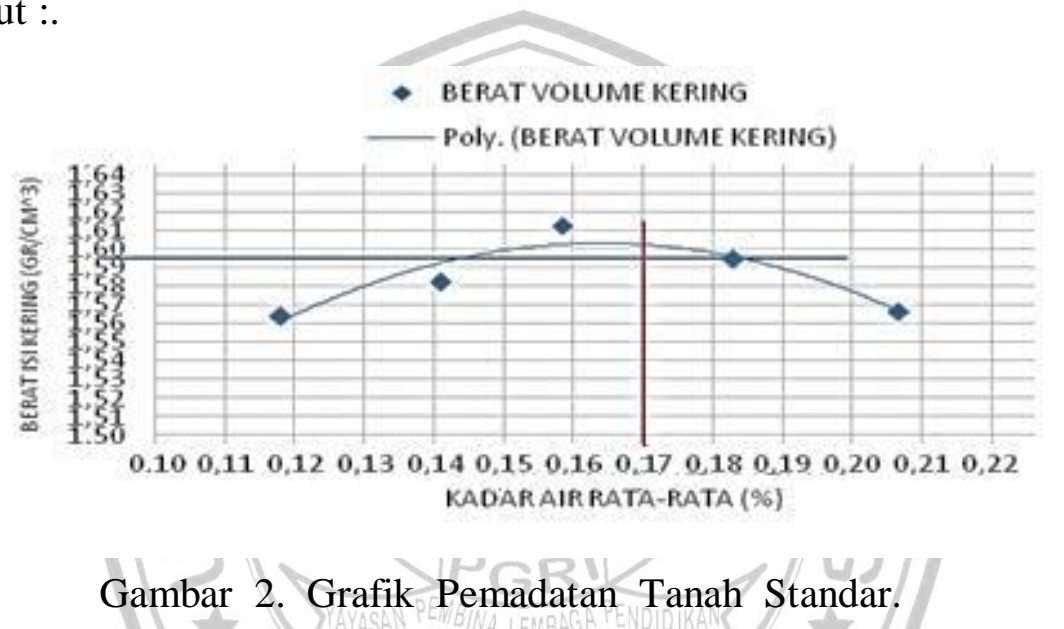

Sampel tanah yang sudah ditambah minyak mentah (crude oil) dengan variasi $0 \%, 5 \%, 10 \%, 15 \%$, dan 20\% dilakukan 3 kali pengujian dirert shear dengan 3 beban normal yang berbeda. Beban-beban yang digunakan yaitu sebesar $49 \mathrm{kPa}$, $98 \mathrm{kPa}$ dan $197 \mathrm{kPa}$ untuk melakuakan pengujian dirert shear.

Hasil pengujian direct shear diperoleh data gaya geser, pergeseran horizontal, regangan dan tegangan geser. Data uji direct shear tanah dianalisis untuk mendapatkan parameter kuat geser tanah. Tegangan geser dihitung dengan membagi nilai gaya geser dari pengujian direct shear dengan luas sampel tanah.

Kemudian nilai dari tegangan geser dan pergeseran horizontal setiap sampel tanah pada setiap pembebanan diplot dalam satu grafik hubungan antara pergeseran horizontal dan tegangan geser. Pada Grafik di bawah ini diberikan grafik hubungan antara pergeseran horizontal dan tegangan geser untuk tanah lempung ditambah minyak mentah (crude oil) 5\%. 


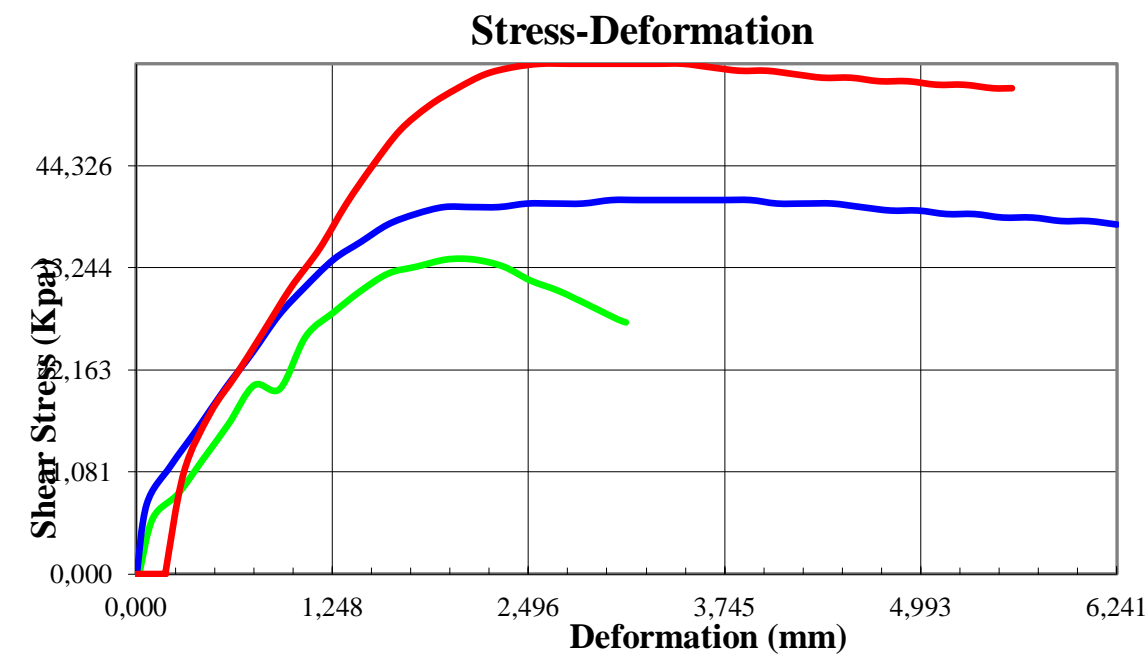

Gambar 3 : Grafik Hubungan Antara Pergeseran Horizontal dan Tegangan Geser Sampel Minyak Mentah (Crude Oil) 5\%.

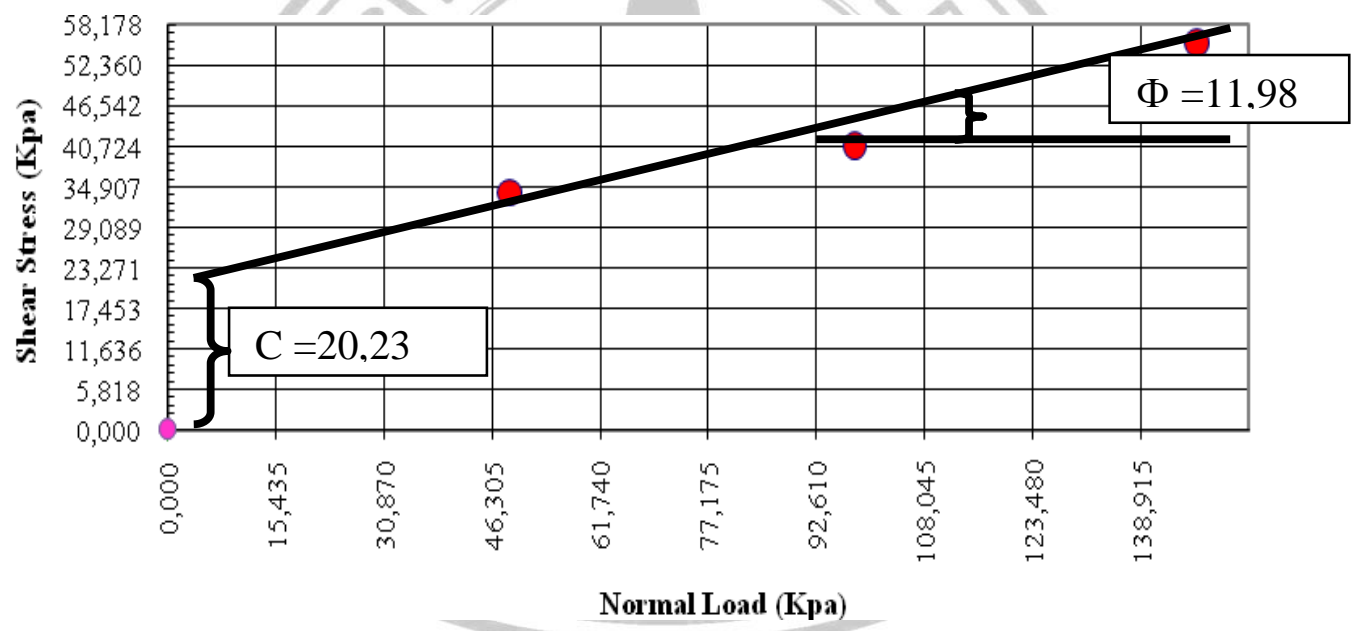

Gambar 4 : Grafik Hubungan Antara Tegangan Normal dan Tegangan Geser Maksimum Sampel Minyak Mentah (Crude Oil) 5\%.

Tabel 2. Nilai Kohesi (c) dan Sudut Geser Dalam $(\phi)$

\begin{tabular}{ccc}
\hline Kode & $\begin{array}{c}\text { Nilai Kohesi (c) } \\
(\mathbf{k P a})\end{array}$ & $\begin{array}{c}\text { Sudut Geser Dalam }(\boldsymbol{\phi}) \\
(\mathbf{0})\end{array}$ \\
\hline Tanah Asli 0\% & 5,5 & 19,8 \\
MM 5\% & 20,23 & 11,98 \\
MM 10\% & 7,30 & 29 \\
MM 15\% & 0 & 0 \\
MM 20\% & 0 & 0 \\
\hline
\end{tabular}


Tabel 3. Nilai Kuat Geser $(\tau)$.

\begin{tabular}{|c|c|}
\hline Kode & Nilai Kuat Geser $(\tau)(\mathbf{k P a})$ \\
\hline Tanah Asli 0\% & 6,74 \\
\hline MM 5\% & 21,10 \\
\hline MM $10 \%$ & 8,7 \\
\hline MM $15 \%$ & 0 \\
\hline MM 20\% & 0 \\
\hline
\end{tabular}

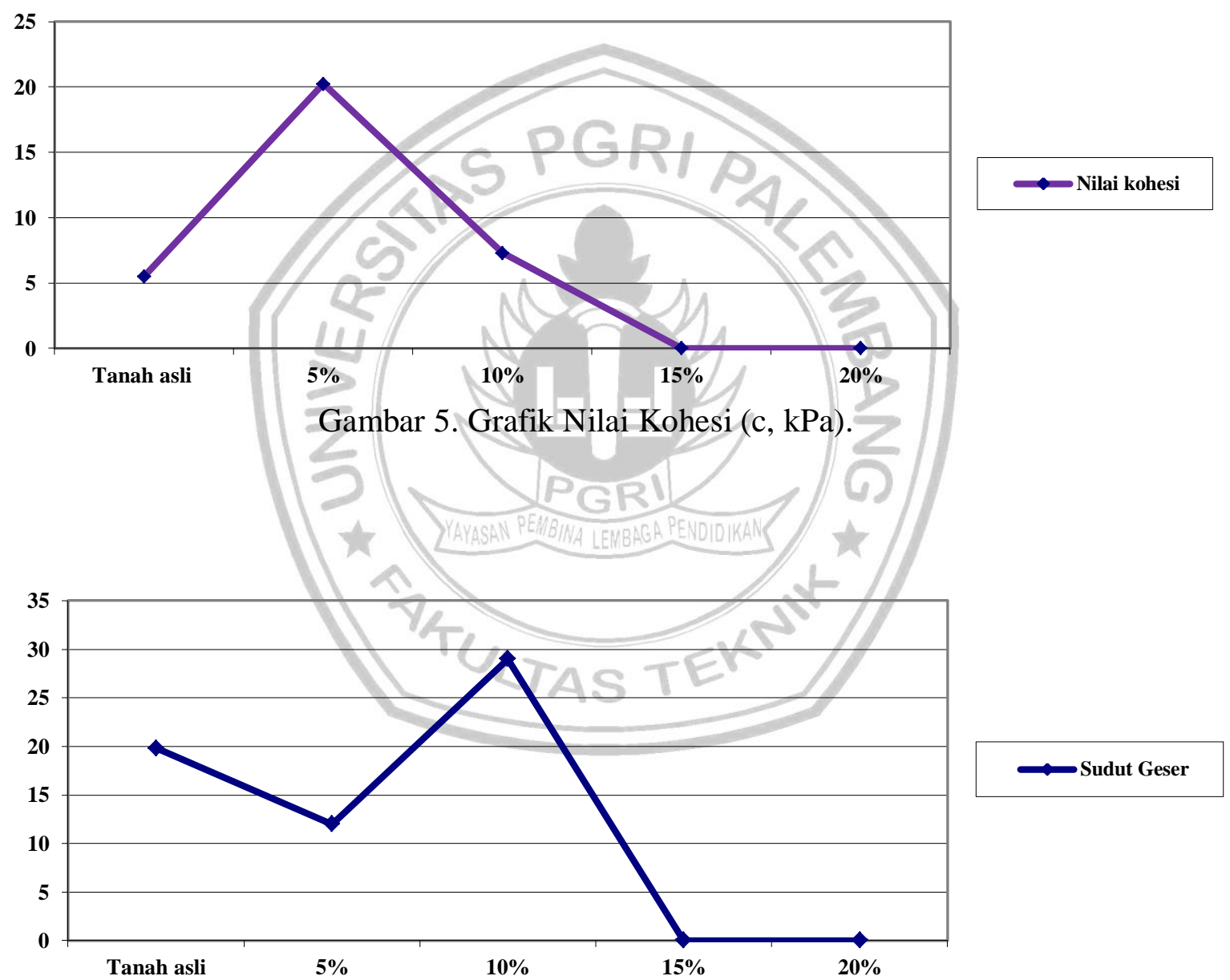

Gambar 6. Grafik Sudut Geser Dalam (ф). 


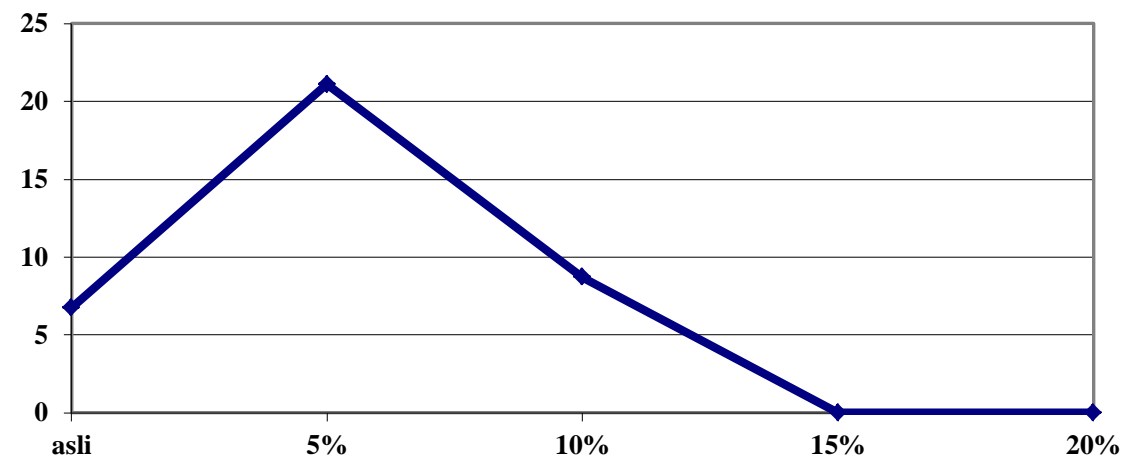

$\longrightarrow$ Nilai Kuat Geser

Gambar 7. Grafik Kuat Geser $(\tau)$.

Pada Grafik di atas, dapat diketahui nilai kohesinya (c) sebesar 20,23 kPa dan sudut geser dalamnya $(\phi)$ sebesar $11,98^{\circ}$. Hasil pengujian terhadap index properties menunjukkan bahwa tanah yang diambil dari daerah Makarti Jaya Kabupaten Banyuasin memiliki kadar air asli $(\hat{\omega})$ sebesar $116,615 \%$, berat jenis tanah $\left(\mathrm{G}_{\mathrm{s}}\right)$ sebesar $1,81 \mathrm{gr} / \mathrm{cm}^{3}$. Dimana dari hasil percobaan pemadatan tanah standar didapat kadar air optimum (⿳亠丷) 18 $\%$ yang digunakan untuk pengujian direct shear.

Adapun rekapitulasi nilai dari kohesi (c), sudet geser dalam ( d dan kuat geser $(\tau)$

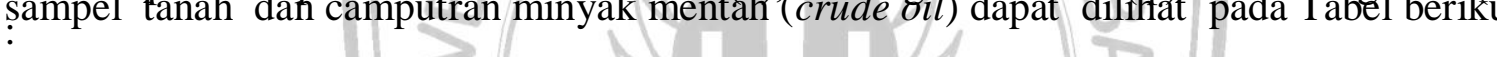
Tabel 4. Rekapitulasi Nilai Dari Kohesi (c), Sudut Geser Dalam (ф) dan Kuat Geser $(\tau)$.

\begin{tabular}{c|cccc}
\hline Kode & $\begin{array}{c}\text { Kohesi } \\
(\mathbf{c}, \mathbf{k P a})\end{array}$ & $\begin{array}{c}\text { Sudut Geser } \\
\text { Dalam }(\mathbf{\phi}, \boldsymbol{)}\end{array}$ & $\begin{array}{c}\text { Kuat Geser } \\
\text { Tanah }(\boldsymbol{\tau}, \mathbf{k P a})\end{array}$ \\
\hline Tanah Asli 0\% & 5,5 & 19,8 & 6,74 \\
MM 5\% & 20,23 & 11,98 & 21,10 \\
MM 10\% & 7,30 & 29 & 8,7 \\
MM 15\% & 0 & 0 & 0 \\
MM 20\% & 0 & 0 & 0 \\
\hline
\end{tabular}

Dari tabel di atas nilai kohesi maksimum terjadi pada sampel tanah yang dicampur dengan minyak mentah (crude oil) sebanyak $5 \%$ yaitu 20,23 kPa, dibandingkan dengan tanah asli yaitu $5,5 \mathrm{kPa}$. Nilai sudut geser maksimum dalam (ф) terjadi pada sempel tanah yang dicampur dengan minyak mentah (crude oil) sebanyak $10 \%$ yaitu $29^{\circ}$ ibandingkan dengan nilai sudut geser tanah asli alam (ф) yaitu 19,8. Nilai kuat geser $(\tau)$ maksimum terjadi pada sampel tanah yang dicampur dengan minyak mentah (crude oil) sebanyak $5 \%$ yaitu $21,10 \mathrm{kPa}$, yang dibandingkan dengan nilai kuat geser $(\tau)$ tanah asli yaitu $6,74 \mathrm{kPa}$. Berdasarkan Nilai kohesi (c) dari grafik bahwa pada campuran minyak mentah (crude oil) $5 \%$ mengalami kenaikan. Nilai sudut geser dalam ( $\phi$ ) pada Gambar 4.5. terlihat bahwa campuran minyak mentah (crude oil) $5 \%$ mengalami penurunan, itu terjadi karena tanah memiliki nilai kohesi (c) yang tinggi karena antara partikel antar butir tanah terikat sangat kuat. Terlihat pada campuran minyak mentah (crude oil) $5 \%$ mengalami kenaikan, kenaikan ini terjadi karena minyak mentah berhasil mengikat tanah 
bermateri organik terhadap lempung. Hasil pada pengujian direct shear sampel tanah dengan persentase $15 \%$ dan $20 \%$ tidak dapat dilakuakan karena tanah tidak solid dan rapuh dikarenakan kadar minyak mentah (crude oil) terlalu banyak sehingga tanah menjadi sanagat lembek dari sebeluumnya, sehingga hasil pengujian sampel tanah dengan kadar campuran $15 \%$ dan $20 \%$ tidak dapat diketahui nilai kuat gesernya.

\section{KESIMPULAN}

1. Dengan kadar air asli (ڤ்) yang tinggi yaitu $116,615 \%$ dan berat jenis tanah (Gs) yang rendah yaitu $1,81 \mathrm{gr} / \mathrm{cm}^{3}$, tanah di daerah Makarti Jaya tidak cocok untuk konstruksi jalan

2. Tanah yang dicampur dengan minyak mentah (crude oil) menghasilkan :

a) Nilai kohesi (c) maksimum $20,23 \mathrm{kPa}$ pada campuran $5 \%$

b) Nilai sudut geser maksimum dalam $(\phi)$ yaitu $29^{\circ}$ pada campuran $10 \%$

c) Nilai kuat geser $(\tau) 21,10 \mathrm{kPa}$ pada campuran $5 \%$

3. Tanah daerah Makarti Jaya yang dicampur minyak mentah (crude oil) dengan kadar persentase $15 \%$ dan $20 \%$ tidak dapat di uji dengan alat direct shear dikarenakan sampel tidak solid dan rapuh sehingga nilai kuat gesernya tidak dapat diketahui.

4. Minyak mentah (crude oil) pada persentase $5 \%$ disimpulkan dapat mengubah sifat tanah daerah Makarti Jaya yang semulanya lembek menjadi lebih keras dan dapat diterapkan di jalan tanah daerah tersebut.

\section{DAFTAR PUSTAKA}

Banta Chairullah, 2011. Stabilisasi tanah lempung lunak untuk material tanah dasar sub grade dan sub base jalan raya. Jurnal Teknik Sipil Universitas Syiah Kuala, 1(1) ; 61-70

Bowles, J.E., 1993. Sifat-sifat Fisis dan Geoteknis Tanah, Terjemahan: JK. Hainim, Jakarta: Erlangga

Braja M Das, 1995. Mekanika Tanah ( Prinsip-Prinsip Rekayasa Geoteknis) Jilid 1, Jakarta : Erlangga

Hardiyatmo, H.C, 2002. Mekanika Tanah 1, Edisi Ketiga, Gadjah Mada University Press ; Yogyakarta.

Hardiyatmo, H.C, 2002. Mekanika Tanah 2, Edisi Ketiga, Gadjah Mada University Press ; Yogyakarta.

Hardiyatmo, H.C, 2010. Stabilisasi Tanah Untuk Perkerasan Jalan, Gadjah Mada University Press ; Yogyakarta

Pangurinseng Darwis, 2001. Stabilisasi Tanah, Universitas 45 Makassar, Makassar :

Resti Ayu, 2018. Stabilisasi Tanah Merah Dengan Menggunakan Limbah (Gypsum) [Skripsi], Palembang ; Universitas PGRI Palembang. 
Sudjianto, A.T, 2007. Stabilisasi Tanah Lempung Ekspansif Dengan Garam Dapur (NaCI), Jurnal Teknik Sipil Universitas Widyagama, Malang

Supriharyono, M. S., 2000. Pelestarian dan Pengelolaan Sumberdaya Alam di Wilayah Tropis. PT. Gramedia Pustaka Utama, Jakarta

Terzaghi Karl, 1987. Mekanika Tanah Dalam Praktek Rekayasa Jilid 1, Edisi Kedua, Jakarta : Erlangga

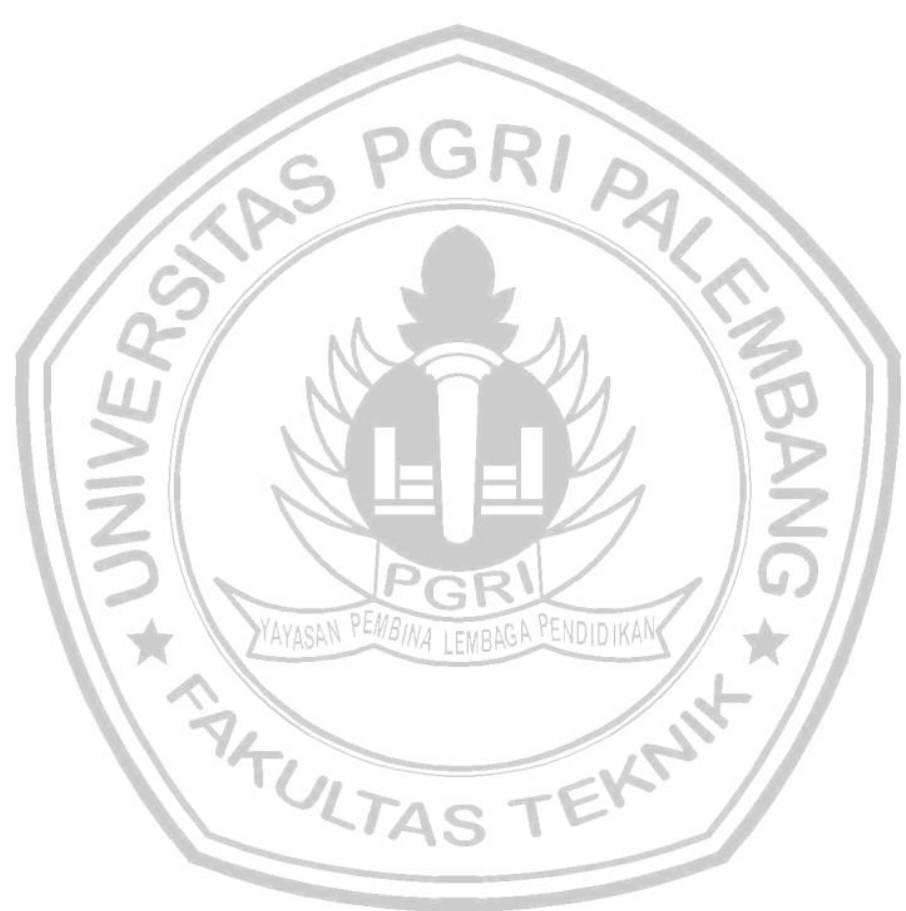

